\title{
OPTIMASI RESPON TUNGGAL PADA PROSES TEXTURING BENANG DTY-150D/96F MENGGUNAKAN METODE TAGUCHI
}

\author{
SINGLE RESPONSE OPTIMIZATION OF DTY-150D/96F YARN TEXTURING \\ PROCESS USING TAGUCHI METHOD
}

\author{
Aris Budianto, Sukarman, Stefanus Bambang Jumawan, Amri Abdulah, Jatira \\ Program Studi Teknik Mesin, Sekolah Tinggi Teknologi Wastukancana, Jl. Cikopak No. 53 Sadang, \\ Purwakarta Jawa Barat 41151 \\ E-mail: sukarman@stt-wastukancana.ac.id
}

Tanggal diterima: 5 April 2020, direvisi: 13 November 2020, disetujui terbit: 2 Desember 2020

\begin{abstract}
ABSTRAK
Artikel ini membahas tentang optimasi parameter proses produksi benang DTY 150D/96F menggunakan mesin texturing merek Oerlikon Barmag. Pada proses pembuatan benang, tenacity merupakan salah satu variabel respon yang harus dikontrol agar konsisten memenuhi spesifikasi 3,8-4,4 g/den. Terdapat beberapa variabel input yang mempengaruhi tenacity dan dua diantaranya adalah draw ratio dan suhu. Eksperimen dilakukan dengan menggunakan orthogonal array L16 Taguchi menggunakan parameter suhu dan draw ratio . Parameter draw ratio yang digunakan adalah $1: 1,23 ; 1: 1,30 ; 1: 1,40 ;$ dan $1: 1,55$. Sedangkan parameter suhu yang digunakan adalah 150 , 160,170 , dan $180^{\circ} \mathrm{C}$. Penelitian ini bertujuan untuk mendapatkan nilai tenacity optimum dari kombinasi parameter proses yang ditetapkan. Metode optimasi ini telah berhasil melakukan perbaikan nilai tenacity dan memenuhi spesifikasi secara konsisten. Nilai tenacity rata-rata DTY 150D/96F tertinggi mencapai 4,25 g/den yang dicapai pada draw ratio dan suhu berturut-turut $1: 1,55$ dan $150^{\circ} \mathrm{C}$. Untuk kedua parameter yang diberikan, draw ratio merupakan parameter yang memberikan dampak tertinggi terhadap tenacity dengan nilai delta sebesar 0,72 . Hasil ini diharapkan bisa digunakan untuk mengembangkan kualitas benang DTY 150D/96F pada aspek-aspek signifikan lainya.
\end{abstract}

Kata kunci: tenacity, DTY 150D/96F, metode Taguchi, S/N ratio, dan draw ratio

\section{ABSTRACT}

This paper discusses the optimization of production process parameters for the DTY 150D/96F yarn using the Oerlikon Barmag texturing machine. In the yarn manufacturing process, tenacity is one of the response variables controlled to consistently meet the specifications, namely between 3.8-4.4 grams/den. Several input variables affect tenacity and two of them are the draw ratio and temperature. Experiments were carried out using the L16 Taguchi orthogonal array using parameters, temperature, and draw ratio. The draw ratio used are 1:1.23; 1:1.30; 1:1.40; and 1:1.55. While the temperature parameters used are 150,160,170, and $180^{\circ} \mathrm{C}$. This study aims to obtain the optimum tenacity value from a combination of the specified process parameters. This optimization method has successfully improved the tenacity value and consistently meets specifications. The highest average tenacity value of DTY 150D/96F reached $4.25 \mathrm{~g} /$ den, which was achieved at the draw ratio and temperature of $1: 1.55$ and $150^{\circ} \mathrm{C}$, respectively. For parameters given, the draw ratio has the highest impact on the tenacity with a delta value of 0.72. These results are expected to improve the yarn quality of the DTY 150D/96F in other significant aspects.

Keywords: tenacity, DTY 150D/96F, Taguchi method, S/N ratio, and draw ratio

\section{PENDAHULUAN}

Pada proses pembuatan benang, texturing adalah metode di mana struktur padat dari benang filamen secara konstan diubah untuk memberi tekstur pada bundel filamen, yang akan memberikan pemintalan benang dengan fitur kenyamanan yang lebih baik pada kain yang dibuat dari bahan dasarnya. ${ }^{1}$ Benang drawn textured yarn (DTY) diperoleh saat poliester partially oriented yarn (POY) dipilin (twisted) dan ditarik (drawn) secara bersamaan. ${ }^{2}$ Proses draw-texturing POY dilakukan secara simultan menggunakan perangkat friction-twisting berdasarkan grup disk yang saling berhubungan dan beroperasi pada kecepatan hingga $1000 \mathrm{~m} / \mathrm{menit}$ yang sering diadopsi untuk menghasilkan benang false-twist textured. ${ }^{3}$ DTY mempunyai tekstur yang lebih lembut dibandingkan dengan tipe benang partially oriented yarn (POY) ataupun benang full draw yarn (FDY). Benang tekstur memberi kesan lembut seperti wol serta 
meningkatkan kehangatan dan kenyamanan kain. ${ }^{4}$ DTY lebih dikenal sebagai serat sintetis dengan nama dagang polyester (PE). Produk ini terbentuk karena adanya reaksi esterifikasi antara purified terephthalic acid (PTA) dan ethylene glycol (EG) sehingga menghasilkan lelehan polimer bersifat direct atau indirect berupa chips yang kemudian diubah bentuknya menjadi POY. ${ }^{5}$ POY merupakan bahan baku benang yang pemakaiannya harus disempurnakan dengan proses texturizing.

Proses pembuatan false-twist textured yarn dapat diteliti berdasarkan tiga parameter utama, yaitu tension, twist, dan suhu. Sifat benang tekstur dapat diubah dengan memodifikasi parameter draw ratio, D/Y ratio, dan suhu. ${ }^{6}$ Beberapa variabel respon penting pada produk DTY meliputi kekuatan tarik benang/tenacity $\alpha_{s}$ dengan satuan $\mathrm{g} / \mathrm{den}$ atau $\mathrm{cN} /$ tex, nomer benang/denier dengan satuan den, engineering stress dengan satuan $\mathrm{cN} / \mathrm{cm}$, dan mulur/elongation dalam \%. ${ }^{7}$

Metode Taguchi merupakan metode statistik yang dikembangkan oleh Genichi Taguchi untuk meningkatkan kualitas, yang awalnya dikembangkan di industri tekstil. ${ }^{8}$ Metode Taguchi lebih disukai sebagai alat pemodelan karena mempelajari pengaruh parameter proses individu serta hubungan antara parameter proses pada respon multi-output. ${ }^{9}$ Metode Taguchi menyediakan metode yang efisien, terstruktur, dan dapat diandalkan untuk desain serta pengoptimalan kinerja, kualitas, dan biaya. ${ }^{10}$ Signifikansi parameter proses pada respon keluaran ditentukan dengan menggunakan ANOVA. Optimasi metode Taguchi telah terbukti efektif digunakan untuk melakukan peningkatan pada industri manufaktur, seperti proses pengelasan, resistance spot welding, machining, painting process, dan masih banyak proses lainnya. $9,11,12,13$

Penelitian optimasi proses produksi dengan objek benang belum banyak dilakukan. Kaynak et al. (2015) melakukan penelitian optimasi pada benang POY 150D/96F dengan menggunakan variabel draw ratio sebagai input, sedangkan variabel respon yang diteliti adalah respon crimp, tenacity, dan dyeing. Draw ratio yang digunakan adalah 1,55; 1,60; dan 1,65. Metode penelitian menggunakan analisis One-way ANOVA. Analisis ANOVA dilakukan untuk menentukan data statistik yang signifikan dari sett weft dan filament kehalusan pada filament force dan karakteristik elongation untuk tiga tipe benang yang berbeda. ${ }^{14}$ Penelitian lanjutan serat DTY dilakukan oleh Y1lmaz et al. (2018). Penelitian menggunakan metode multiple linear regression (MLR) bertahap dan membentuk model artificial neural network (ANN) untuk memprediksi karakteristik benang. Penelitian dilakukan untuk memprediksi nilai tensile properties (khususnya breaking strength dan breaking elongation) dari PES/CV/AN yang digabung dengan Open-End Rotor. Faktor-faktor yang efektif mempengaruhi respon adalah rasio campuran serat (enam level), kerapatan linier (tiga level), metode pencampuran (mesin carding dan NI), DTY Intermingling (IM), DTY Soft Interm draw frame), dan jumlah lintasan dalam draw frame (satu dan dua kali lintasan). Hasil analisis didapatkan bahwa untuk prediksi breaking strength, model ANN memiliki hasil yang sedikit lebih baik dibandingkan medel MLR dan ketepatan prediksi yang signifikan untuk breaking elongation. ${ }^{15}$ Dharmsari et al. (2018) melakukan penelitian proses texturing polyester 86 dtex/F36 POY dengan membandingkan proses steam-jet dan air-jet. Hasil penelitian menyimpulkan bahwa benang tekstur steam-jet lebih ekonomis untuk diproduksi dibandingkan benang tekstur air-jet. Selain itu, cairan alternatif yang ramah lingkungan, seperti biomassa dapat digunakan untuk menghasilkan uap. $^{16}$

Berbeda dengan penelitian sebelumnya, penelitian ini menggunakan metode Taguchi untuk melakukan optimasi proses pembuatan benang DTY 150D/96F. Pengaturan parameter draw ratio dan suhu yang digunakan saat ini tidak konsisten memenuhi spesifikasi tenacity 4,1 $\pm 0,3 \mathrm{~g} / \mathrm{den}$. Metode penelitian dilakukan dengan menggunakan 2-variabel dan 4-level percobaan. Penelitian ini dilakukan untuk mendapatkan tenacity optimum pada proses pembuatan benang drawn texturized yarn (DTY). Karakteristik data yang akan digunakan pada penelitian ini adalah larger is better.

\section{Tenacity dan breaking elongation (strain)}

Tenacity adalah beban putus (load at break) suatu benang yang dinyatakan dalam $\mathrm{cN}$ dibagi dengan kerapatan linear serat yang diekspresikan dalam tex sehingga tenacity memiliki satuan cN/tex. ${ }^{3,5,17}$ Dengan definisi ini maka tenacity dihitung dengan menggunakan Persamaan 1 berikut: ${ }^{5}$

$$
\text { Tenacity }=\alpha_{s}=\frac{F}{L D}
$$

dimana $F$ adalah load at break dalam satuan $\mathrm{cN}$, LD merupakan linear density dalam satuan tex (g/1000 m). Satuan tenacity yang akan digunakan dalam penelitian ini adalah gram per den (g/den) dan dikonversikan menjadi $\mathrm{cN} /$ tex dimana $\mathrm{g} / \mathrm{den}=$ $0,981 \times$ (cN/tex). ${ }^{7}$ Sampel untuk uji kekuatan tarik (tenacity) dan break strain dibuat dengan ukuran $200 \times 20 \mathrm{~mm}^{18}$ Pada benang mélange, tenacity secara signifikan dipengaruhi oleh microfiber. ${ }^{19,20,21}$

Nilai sifat dari kerapatan linear serat atau yang biasa dikenal dengan kehalusan serat dapat berkisar dari sekitar 130-230 mtex. Semakin tinggi nilainya maka serat akan semakin kasar. Dalam penelitian serat, istilah "keuletan" digantikan 
dengan istilah "stress specific $(\delta s)$ ". Dalam penelitian serat dan polimer, tegangan tarik dapat dinyatakan dalam bentuk beban per unit kepadatan linier (massa per satuan panjang). Tegangan tarik pada penelitian ini disebut sebagai engineering stress $\left(\delta_{\mathrm{s}}\right)$ yang dirumuskan sebagaimana Persamaan $2:^{3}$

$$
\delta_{s}=\frac{F}{A_{0}}
$$

dimana $F$ adalah load break dalam $\mathrm{cN}, \delta_{s}$ adalah engineering stress dalam $\mathrm{cN} / \mathrm{cm}^{2}$, dan $A_{\sigma}$ adalah cross section-area dalam $\mathrm{cm}^{2}$.

Breaking Elongation-at break (break strain) adalah persentase perpanjangan putus (regangan) yang nilainya dihitung dengan Persamaan 3 berikut: ${ }^{3}$

$$
\mathrm{E}_{\text {at break }}=\frac{\Delta \mathrm{L}_{\text {至enk }}}{\mathrm{L}_{0}} \times 100 \%
$$

dimana $\Delta L_{\text {break }}$ adalah selisih panjang benang setelah pengujian dikurangi panjang benang sebelum pengujian dalam satuan $\mathrm{m}$, dan $L_{o}$ adalah panjang benang awal (sebelum pengujian) dalam satuan $m$.

\section{Winding Time dan Draw ratio}

Winding/doffing time merupakan proses terakhir pembuatan benang DTY. Benang yang sudah berbentuk textured yarn tergulung pada paper tube yang diputar pada drum/bowl/take-up. Lama proses winding bergantung pada berat dan nomor benang yang ditentukan. Persamaan 4 berikut ini digunakan untuk mengitung winding time $(W T):^{3}$

$$
\mathrm{WT}^{\mathrm{N}}=\frac{\text { massa tiap bobbin } \times 9000}{\text { Speed } \times \text { Denier }}
$$

dimana WT adalah winding time dalam satuan $\mathrm{m} /$ detik, $\mathrm{m}_{\mathrm{b}}$ adalah massa tiap bobbin dalam gram, dan speed dalam satuan $\mathrm{m} / \mathrm{menit}$. Produk akhir benang DTY tersaji pada Gambar 1.
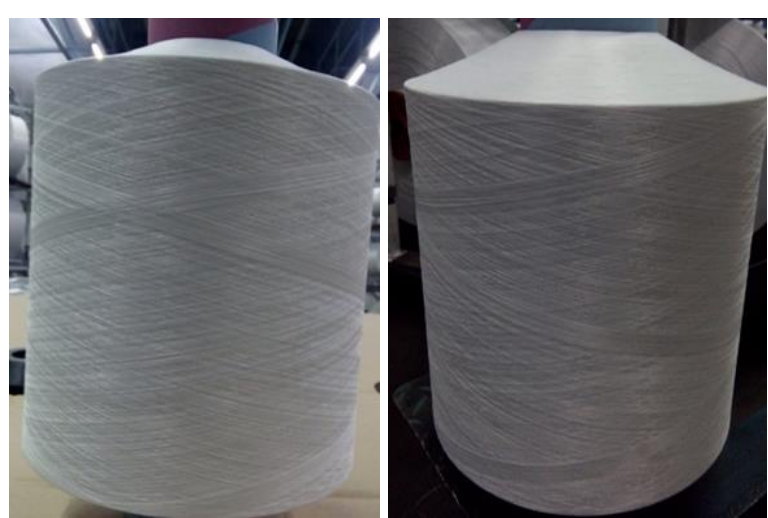

Gambar 1. Benang DTY setalah melalui proses winding
Draw ratio merupakan variabel kedua yang sangat mempengaruhi mutu DTY (denier, tenacity, breaking elongation, dan variabel respon lainya). ${ }^{22}$ Draw ratio $(S)$ didefinisikan sebagai perbandingan antara take-up velocity $\left(V_{L}\right)$ dalam satuan mpm (meter per minutes) dengan extrusion velocity $\left(V_{o}\right)$ dalam satuan mpm (meter per minutes). Draw ratio bisa dihitung dengan Persamaan 5 berikut: ${ }^{5,6}$

$$
S=\frac{V_{L}}{V_{0}}
$$

\section{METODE PENELITIAN \\ Alat dan Bahan}

Penelitian ini menggunakan benang DTY 150D/96F dengan spesifikasi minimum 150 denier dan 96 filamen. Optimasi dilakukan pada proses produksi DTY menggunakan treatment single heater. Pada proses ini digunakan dua pemanas (heater) namun yang beroperasi pada suhu tinggi hanya satu pemanas. Spesifikasi DTY 150D/96F tersaji pada Tabel 1 berikut:

Tabel 1. Spesifikasi material DTY 150D/96F

\begin{tabular}{lrr}
\hline Spesifikasi & Satuan & \multicolumn{1}{l}{ Nilai } \\
\hline Linear Density & Denier & $160 \pm 3,0$ \\
Filament Force & $\mathrm{N}$ & $\geq 5,1$ \\
Tenacity & g/den & $4,1 \pm 0,3$ \\
Elongation & $\%$ & $21 \pm 7,0$ \\
\hline
\end{tabular}

Penelitian ini menggunakan mesin texturing merek Oerlikon Barmag dengan model/tipe EFK Texturing Machine. Mesin buatan Jerman tahun 2012 ini memiliki 240 mata pintal. Spesifikasi lengkap mesin yang digunakan tersaji pada Tabel 2 berikut:

Tabel 2. Spesifikasi mesin texturing

\begin{tabular}{ll}
\hline Parameter & Spesifikasi \\
\hline Wiring diagram & EFK-250-15053P \\
Control voltage & $220 \mathrm{~V}$ \\
Supply & $380 \mathrm{~V}-$ Main Fuse 500A \\
Frequency & $58 \mathrm{~Hz}$ \\
\hline
\end{tabular}

Sebelum eksperimen dimulai, semua kondisi mesin dan peralatan yang digunakan harus dicek dan dipastikan memenuhi persyaratan keamanan. Penelitian eksperimental ini menggunakan 2 variabel dan 4 level percoban. Parameter suhu disetting pada nilai $150,160,170$, dan $180^{\circ} \mathrm{C}$. Sementara pada parameter draw ratio diatur pada ratio $1: 1,23 ; 1: 1,30 ; 1: 1,40 ;$ dan $1: 1,55$. Proses pengaturan draw ratio dilakukan pada extrusion velocity tetap $450 \mathrm{mpm}$, sedangkan take-up velocity diatur sesuai dengan draw ratio, yaitu 552, 584, 630, dan $700 \mathrm{mpm}$. Parameter optimasi untuk setiap level yang digunakan tersaji pada Tabel 3 berikut: 
Tabel 3. Parameter optimasi Taguchi

\begin{tabular}{lrrrr}
\hline \multirow{2}{*}{ Faktor } & \multicolumn{4}{c}{ Level } \\
\cline { 2 - 5 } & \multicolumn{1}{c}{ I } & \multicolumn{1}{c}{ II } & \multicolumn{1}{c}{ III } & \multicolumn{1}{c}{ IV } \\
\hline Draw ratio & $1: 1,23$ & $1: 1,30$ & $1: 1,40$ & $1: 1,55$ \\
Suhu $\left({ }^{\circ} \mathrm{C}\right)$ & 150 & 160 & 170 & 180 \\
\hline
\end{tabular}

Proses optimasi benang DTY diawali dengan pengaturan kecepatan feed roll-1 $\left(V_{L}\right)$ pada kecepatan $450 \mathrm{~m} / \mathrm{menit}$. Pengaturan kondisi saat ini dilakukan pada draw ratio $1: 1,23$ dan suhu $180^{\circ} \mathrm{C}$. Proses selanjutnya yaitu dengan melakukan pengaturan temperatur pada primary heater antara $150-180^{\circ} \mathrm{C}$. Pada penelitian ini, suhu awal di-setting pada suhu $150^{\circ} \mathrm{C}$ dan selanjutnya benang DTY masuk ke proses positorq sebelum masuk ke feed roll-2. Pengaturan kecepatan feed roll-2 diatur lebih tinggi dari feed roll-1 yang besarnya dihitung menggunakan Persamaan 5, sehingga didapat draw ratio sesuai dengan Tabel 3. Untuk mendapatkan draw ratio 1:1,23 maka kecepatan Vo dihitung sebagai berikut:

$$
\begin{aligned}
& S=\frac{V_{L}}{V_{o}} \leftarrow \rightarrow \frac{1}{1,23}=\frac{450 \mathrm{mppm}}{V_{o}} \\
& V_{o}=1,23 \times 450 \mathrm{mpm}=553,5 \approx 554 \mathrm{mpm}
\end{aligned}
$$

Tabel 4. Draw ratio, $V_{L}$ dan $V_{o}$

\begin{tabular}{lcccc}
\hline \multirow{2}{*}{ Faktor } & \multicolumn{4}{c}{ Level } \\
\cline { 2 - 5 } & I & II & III & IV \\
\hline Draw ratio & $1: 1,23$ & $1: 1,30$ & $1: 1,40$ & $1: 1,55$ \\
$V_{L}($ mpm $)$ & 450 & 450 & 450 & 450 \\
$V_{o}($ mpm $)$ & 554 & 584 & 630 & 700 \\
\hline
\end{tabular}

Detail perhitungan $V o$ untuk setiap draw ratio tersaji pada Tabel 4.

Proses selanjutnya, bahan baku masuk ke proses secondary heater, feed roll-3, dan proses oiling roll. Proses terakhir dari produksi DTY adalah proses winding. DTY yang diproduksi memiliki masa tiap bobbin 5500 gram, denier 160 denier (atau 160 gram/9000 m), jika speed yang digunakan adalah 553,5 mpm (meter per menit), maka winding time yang dibutuhkan dihitung dengan Persamaan 4.

$$
\begin{aligned}
& \text { WT }=\frac{5500 \mathrm{gram} \times 9000}{553,5 \frac{\mathrm{m}}{\text { menit }} \times 160 \frac{\mathrm{gram}}{9000 \mathrm{~m}}} \\
& W^{\prime}=0,0621 \text { menit }=3,73 \text { detik }
\end{aligned}
$$

Density DTY dipengaruhi oleh kelembaban udara. Kontribusi utama dari pengkondisian datang dengan peningkatan kadar air benang serta peningkatan berat kemasan. ${ }^{23}$ Semakin tinggi kelembaban udara maka density juga akan cenderung naik. Proses produksi DTY ditunjukkan pada Gambar 2.

\section{Metode Pengujian}

Pengujian tenacity dilakukan dengan menggunakan mesin automatic tensile tester merek STATIMAT ME+. Mesin ini memiliki kapasitas beban $1000 \mathrm{~N}$ dengan kecepatan penarikan 1-5000 $\mathrm{mm} / \mathrm{menit}$. Mesin ini dilengkapi 2 pneumatic yarn clamps dengan jarak minimum antar gauge $50 \mathrm{~mm}$ dan traveling gauge sampai $850 \mathrm{~mm}$. Pengujian tenacity dalam penelitian ini mengacu pada standar ASTM D 2256 Standard Test Method for Tensile Properties of Yarns by the Single-Strand Method. ${ }^{24}$ Pengaturan parameter pengujian tenacity mengacu pada Tabel 5.

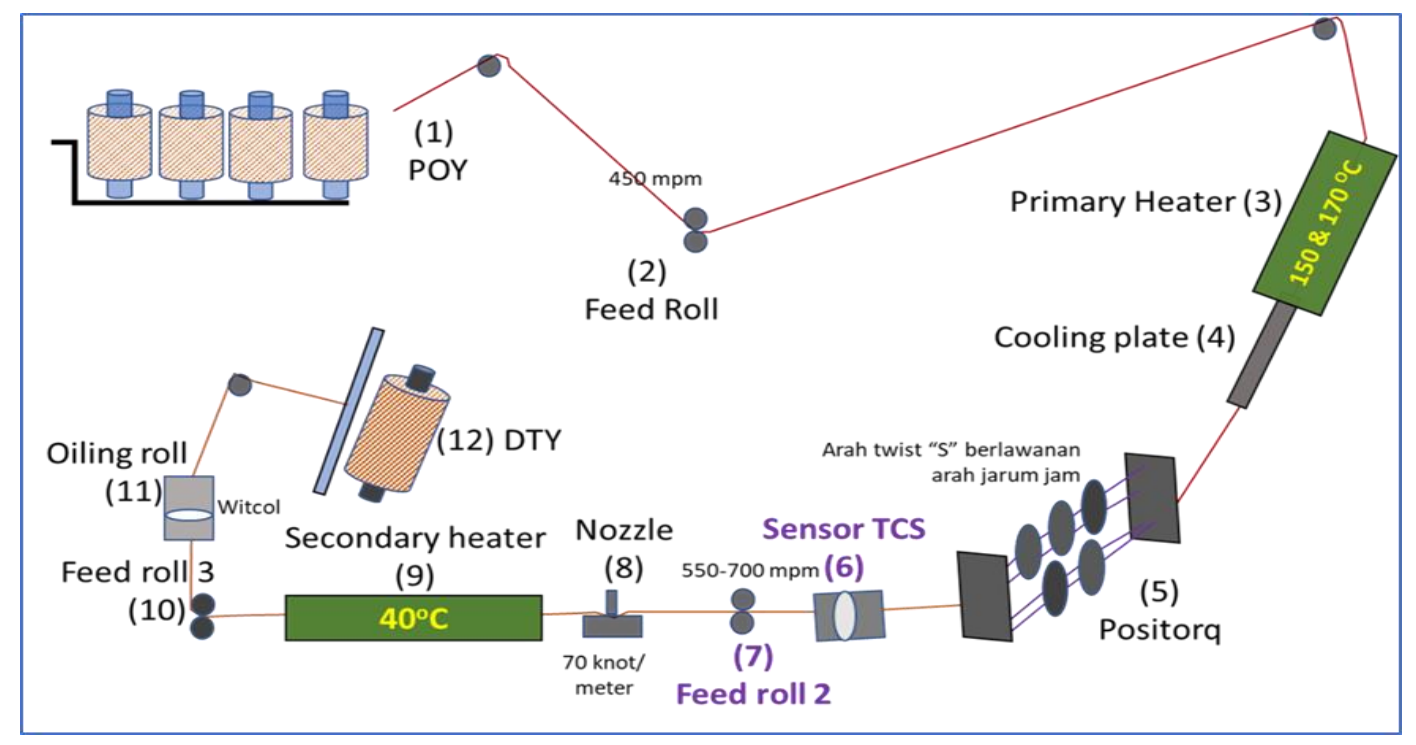

Gambar 2. Skema produksi DTY pada mesin texturing 
Tabel 5. Parameter pengujian tenacity

\begin{tabular}{lcc}
\hline Parameter & ASTM D 2256 & Pengujian \\
\hline Gauge Length $(\mathrm{mm})$ & $500 \pm 5$ & 500 \\
Kecepatan penarikan $(\mathrm{mm} /$ menit $)$ & $300 \pm 10$ & 300 \\
\hline
\end{tabular}

\section{Orthogonal Array (OA)}

Eksperimen Taguchi merupakan metode eksperimental yang telah terbukti efektif untuk melakukan optimasi pada proses-proses manufaktur/produksi yang telah berjalan. Penelitian ini menggunakan 2 faktor yang dikontrol dalam 4 level eksperimen. Pengendalian kedua parameter ini masing-masing memiliki 3 derajat kebebasan/degrees of freedom (didapat dari 4-1=3, dimana 4 merupakan level eksperimen yang digunakan dalam penelitian ini). Derajat kebebasan gabungan dari dua variabel respon adalah 9 yang didapat dari $(\mathrm{k}-1)^{\mathrm{n}}=(4-1)^{2}=9$. Dimana $k$ dan $n$ merupakan tingkat dan jumlah faktor yang digunakan. Orthogonal array L16 $\left(4^{2}\right)$ memiliki derajat kebebasan total sebanyak 15 (didapat dari penjumlahan derajat kebebasan tiap faktor dan gabungan). Derajat kebebasan orthogonal array L16 $\left(4^{2}\right)$ bisa dihitung dengan $k^{n}-1=4^{2}-1=15 .^{25}$ Tabel 6 menunjukkan data pengukuran nilai tiga variabel respon tenacity pada setiap iterasi di variabel input.

Untuk konsistensi data, maka dilakukan tiga pengulangan pada setiap iterasi. Hal ini bertujuan untuk mendapatkan data nilai variabel respon yang akan dianalisis menjadi teruji dan presisi. Variabel respon merupakan variabel bebas yang nilainya tergantung pada variabel input (tetap).

\section{Signal to Noise Ratio (S/N Ratio)}

Istilah $S / N$ ratio dalam eksperimen Taguchi sangat penting. Istilah 'signal' merupakan bagian dari nilai yang diinginkan pada karakteristik output/ variabel respon. Variabel respon pada penelitian ini adalah tenacity. Sedangkan istilah 'noise' mewakili nilai yang tidak diharapkan pada karakteristik output. $S / N$ ratio menunjukkan parameter terbaik yang memberikan nilai karakteristik output terbaik atau optimal. ${ }^{26}$ Perhitungan $S / N$ ratio dilakukan tergantung pada karakteristik kualitas data yang ingin dicapai. Metode Taguchi membagi karakteristik kualitas output ke dalam tiga bagian yaitu smaller is better, larger is better, dan nominal is the best. Persamaan matematik untuk setiap karakterisik output ditunjukkan pada Persamaan 6, 7 , dan $8 .{ }^{25,26}$

Tabel 6. Data eksperimen nilai tenacity R-1, R-2, dan R-3 pada setiap iterasi, $1 \frac{\mathrm{EV}}{\text { tex }}=1,13 \frac{G}{\text { devier }} 28$

\begin{tabular}{|c|c|c|c|c|c|c|}
\hline \multicolumn{2}{|c|}{ Variable } & \multicolumn{3}{|c|}{ TENACITY $\frac{\mathrm{g}}{\mathrm{den}}$} & \multirow{2}{*}{ MEAN } & \multirow{2}{*}{ S/N ratio } \\
\hline Draw ratio & Suhu & R-1 & R-2 & R-3 & & \\
\hline 1 & 1 & 3,86 & 4,09 & 4,10 & 4,02 & 12,07 \\
\hline 1 & 2 & 3,77 & 4,07 & 4,08 & 3,97 & 11,97 \\
\hline 1 & 3 & 3,77 & 3,86 & 4,02 & 3,88 & 11,77 \\
\hline 1 & 4 & 3,22 & 3,77 & 3,77 & 3,59 & 11,02 \\
\hline 2 & 1 & 4,08 & 4,08 & 4,09 & 4,08 & 12,22 \\
\hline 2 & 2 & 4,07 & 4,08 & 4,07 & 4,07 & 12,20 \\
\hline 2 & 3 & 4,03 & 4,07 & 4,03 & 4,04 & 12,13 \\
\hline 2 & 4 & 4,02 & 4,03 & 4,03 & 4,03 & 12,10 \\
\hline 3 & 1 & 4,15 & 4,16 & 4,15 & 4,15 & 12,37 \\
\hline 3 & 2 & 4,10 & 4,15 & 4,10 & 4,12 & 12,29 \\
\hline 3 & 3 & 4,09 & 4,10 & 4,10 & 4,10 & 12,25 \\
\hline 3 & 4 & 4,07 & 4,09 & 4,08 & 4,08 & 12,21 \\
\hline 4 & 1 & 4,16 & 4,20 & 4,38 & 4,25 & 12,55 \\
\hline 4 & 2 & 4,16 & 4,16 & 4,20 & 4,17 & 12,41 \\
\hline 4 & 3 & 4,15 & 4,16 & 4,16 & 4,16 & 12,37 \\
\hline 4 & 4 & 4,15 & 4,15 & 4,16 & 4,15 & 12,37 \\
\hline
\end{tabular}


Smaller is better:

$$
S / N \text { ratio }=-10 \log \sum_{i=1}^{n_{n}} \frac{y_{1}^{2}}{n_{a}}
$$

Larger is better:

$$
\text { S/N ratio }=-10 \log \frac{1}{n_{i \mathbb{1}}} \sum_{i=1}^{n_{i}} \frac{1}{y_{i}^{2}}
$$

Nominal is the best:

$$
S / N \text { ratio }=-10 \log \frac{y^{2}}{s^{2}}
$$

dimana $\bar{y}$ merupakan nilai rata-rata data sedangkan $\mathrm{s}$ adalah standar deviasi.

Tenacity harus memiliki nilai yang tertinggi untuk kinerja terbaik, maka digunakan $S / N$ ratio dengan karakteristik larger is better. Karakteristik larger is better merupakan karakteristik terukur non-negatif dengan nilai ideal tak hingga. Karakteristik ini sering digunakan untuk mengoptimasi data respon seperti kekuatan kontruksi bangunan, sambungan pengelasan, ketahanan korosi, dan lain-lain. Pencapaian nilai tenacity tertinggi menunjukkan kualitas yang dihasilkan merupakan yang terbaik, sehingga $S / N$ ratio dihitung menggunakan Persamaan 8.8,26,27

\section{HASIL DAN PEMBAHASAN \\ Signal to Noise Ratio (S/N ratio)}

Metode Taguchi menggunakan signal to noise ratio ( $S / N$ ratio) untuk menunjukkan sensitivitas karakteristik yang diharapkan untuk faktor input, dalam proses yang terkendali. ${ }^{8}$ Kondisi optimal diperoleh dengan mendefinisikan efek dari masing-masing faktor input pada karakteristik respon. Analisis $S / N$ ratio bertujuan untuk menentukan tingkat yang tepat dari input yang berbeda untuk mencapai respon terbaik.

Tabel 7. S/N ratio karakteristik larger is better

\begin{tabular}{crr}
\hline Level & \multicolumn{1}{c}{ A } & \multicolumn{1}{c}{ B } \\
\hline 1 & 11,71 & 12,30 \\
2 & 12,16 & 12,22 \\
3 & 12,28 & 12,13 \\
4 & 12,43 & 11,93 \\
Delta & 0,72 & 0,38 \\
Rank & 1 & 2 \\
\hline
\end{tabular}

Tabel 7 menunjukkan analisis $S / N$ ratio Minitab untuk setiap iterasi yang diujikan menggunakan karakteristik larger is better. Tabel 7 menunjukkan draw ratio pada level ke-4, yaitu 1:1,55 memiliki pengaruh yang tertinggi, dengan nilai $S / N$ ratio sebesar 12,43 . Pada suhu yang diberikan, pengaturan level ke-1 dengan nilai $150^{\circ} \mathrm{C}$ memiliki pengaruh tertinggi dengan nilai $S / N$ ratio sebesar 12,30. Tabel 7 juga menunjukkan parameter draw ratio memiliki pengaruh yang lebih signifikan dibandingkan suhu. Hal ini dapat dilihat dari nilai delta draw ratio sebesar 0,72 dan nilai delta suhu hanya sebesar 0,38 . Nilai delta didapatkan dari nilai $S / N$ ratio terbesar dikurangi dengan $S / N$ ratio terkecil pada tiap parameter. Sedangan nilai $S / N$ ratio dihitung menggunakan Persamaan 8.

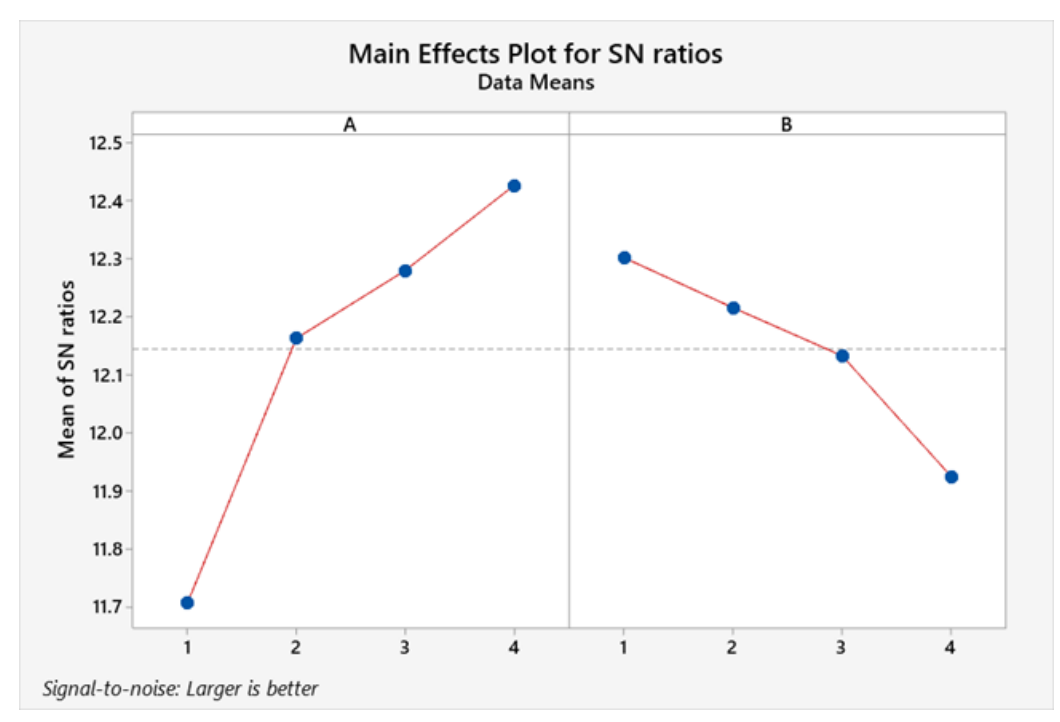

Gambar 3. Grafik S/N ratio rata-rata tenacity software statistik 


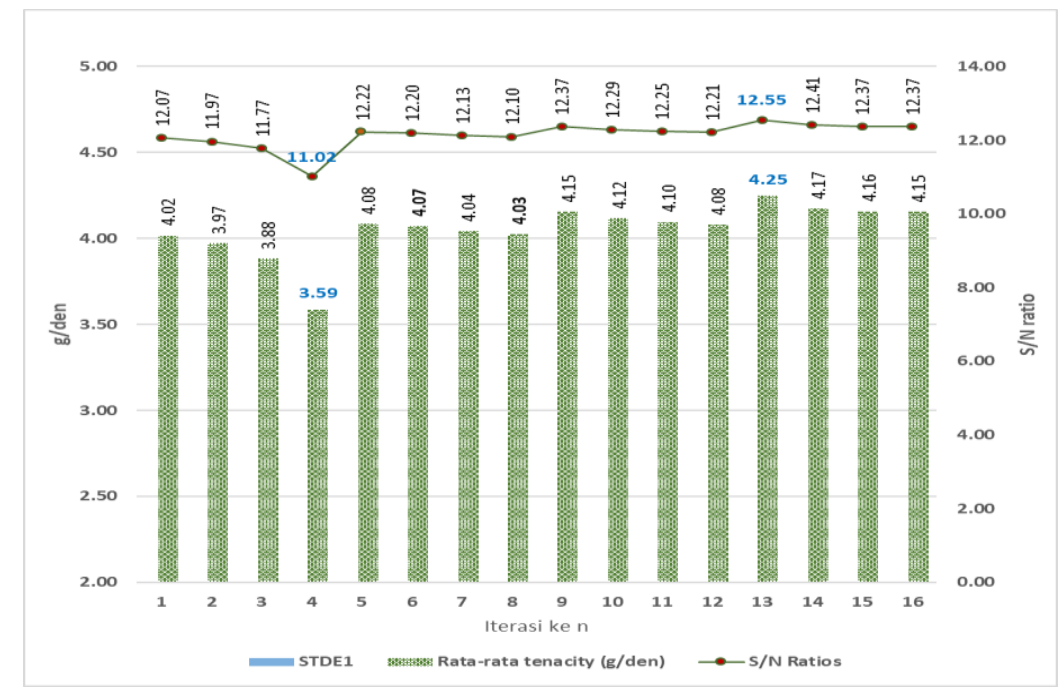

Gambar 4. Grafik S/N ratio dan rata-rata tenacity
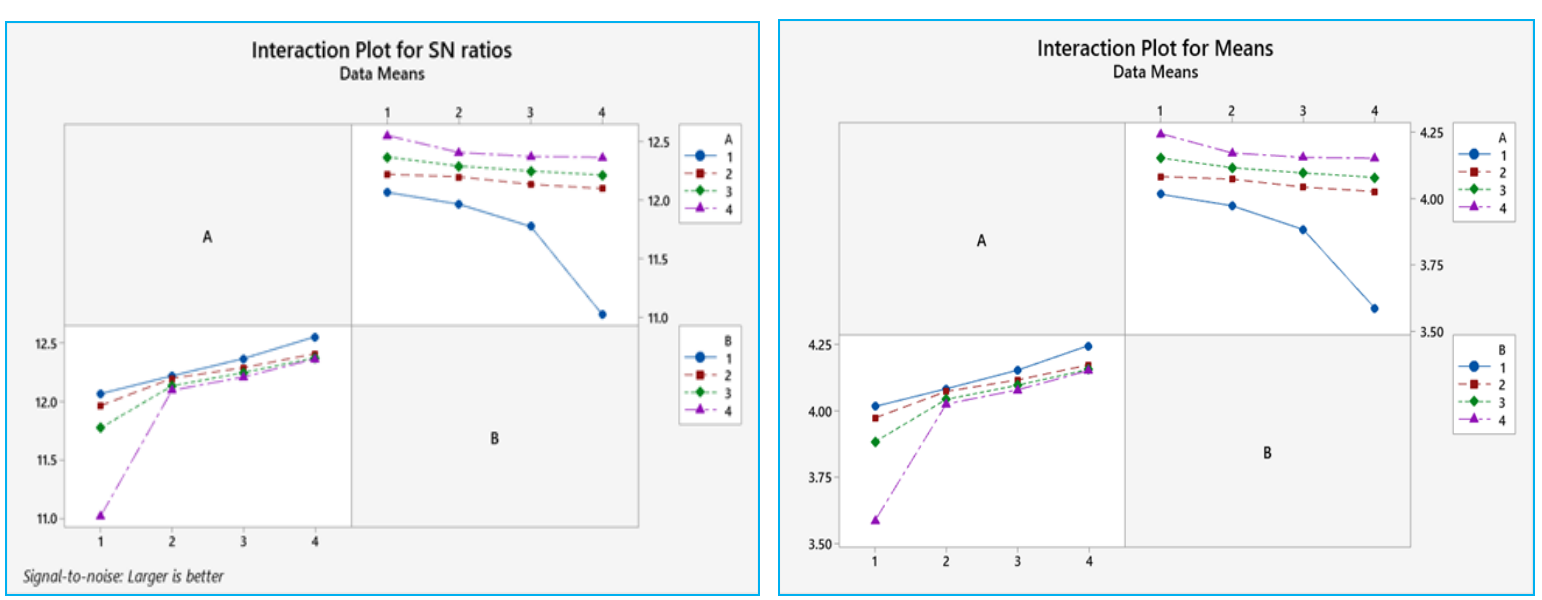

Gambar 5. Grafik interaksi tiap variabel: (a) sumbu $x$-level terhadap sumbu $y-S / N$ ratio dan (b) sumbu $x-$ level terhadap sumbu y-rata-rata nilai tenacity

Tabel 8. Analisis ANOVA untuk R-1, R-2, R-3, dan rata-rata tenacity

Anova tenacity $R-1$

\begin{tabular}{crcccc}
\hline Source & DF & SS & MS & F & P \\
\hline A & 3 & 0,2223 & 0,0741 & 7,209 & 0,005 \\
B & 12 & 0,1233 & 0,0103 & & \\
Total & 15 & 0,3456 & & & \\
\hline
\end{tabular}

Anova tenacity $R-3$

\begin{tabular}{crcccc}
\hline Source & DF & SS & MS & F & P \\
\hline A & 3 & 0,1166 & 0,0389 & 4,322 & 0,028 \\
B & 12 & 0,1080 & 0,0090 & & \\
Total & 15 & 0,2246 & & & \\
\hline
\end{tabular}

Gambar 3 menunjukkan pengaruh draw ratio dan suhu terhadap output. Draw ratio berkontribusi positif terhadap tenacity. Pengaruh suhu terhadap tenacity berbanding terbalik. Hasil ini memperkuat
Anova tenacity $R-2$

\begin{tabular}{|c|c|c|c|c|c|}
\hline Source & DF & SS & MS & $\mathbf{F}$ & $\mathbf{P}$ \\
\hline A & 3 & 0,1096 & 0,0365 & 5,390 & 0,014 \\
\hline B & 12 & 0,0813 & 0,0068 & & \\
\hline Total & 15 & 0,1910 & & & \\
\hline \multicolumn{6}{|c|}{ Anova tenacity untuk mean } \\
\hline Source & DF & SS & MS & $\mathbf{F}$ & $\mathbf{P}$ \\
\hline A & 3 & 0,2223 & 0,0741 & 7,209 & 0,005 \\
\hline B & 12 & 0,1233 & 0,0103 & & \\
\hline Total & 15 & 0,3456 & & & \\
\hline
\end{tabular}

teori bahwa, semakin tinggi draw ratio, maka semakin besar juga nilai tenacity. Semakin tinggi suhunya, maka tenacity akan semakin menurun. Pendekatan lain bisa dikatakan bahwa pengaruh 
draw ratio pada level ke-4 dan suhu pada level ke-1 paling signifikan mempengaruhi respon tenacity dibandingkan pada level lainnya. ${ }^{29,30}$ Gambar 3 merupakan grafik dari software Minitab dari respon $S / N$ ratio untuk respon tenacity berdasarkan Tabel 7.

Gambar 4 menunjukkan grafik nilai $S / N$ ratio dan tenacity rata-rata. Dari grafik ini, terlihat nilai rata-rata respon tenacity tertinggi adalah $4,25 \mathrm{~g} / \mathrm{den}$ dengan nilai $S / N$ ratio sebesar 12,55 . Kondisi ini mengalami peningkatan mutu jika dibandingkan dengan pengaturan parameter pada saat ini, yaitu pengaturan parameter draw ratio dan suhu pada iterasi ke-4. Untuk mendapatkan nilai rata-rata tenacity tertinggi, metode Taguchi menyarankan agar draw ratio dan suhu berturut-turut diatur pada 1:1,55 dan $150^{\circ} \mathrm{C}$. Optimasi Taguchi berhasil meningkatkan kualitas jika dibandingkan dengan pengaturan kondisi sebelumnya.

\section{Analysis of Variance (ANOVA)}

Analisis ANOVA dilakukan terhadap data tenacity pada tiap replikasi dan data rata-rata. Tujuan analisis ANOVA adalah untuk mengidentifikasi parameter yang signifikan dan untuk mengukur pengaruhnya terhadap karakteristik respon. Dalam analisis, dihitung jumlah kuadrat dan varians. Nilai uji- $P$ pada tingkat kepercayaan 95\%. Significance level $\alpha, 5 \%$ digunakan untuk menentukan faktor-faktor signifikan yang mempengaruhi respon dan kontribusi perhitungan persentase. Nilai $P$ yang lebih kecil dari a menunjukkan bahwa variasi parameter proses membuat perubahan besar dalam kinerja. ${ }^{27,31}$

Analisis ANOVA untuk memprediksi pengaruh draw ratio dan suhu terhadap tenacity tersaji pada Tabel 8. Dari Tabel 8 terlihat bahwa semua nilai $P$ pada $R-1, R-2, R-3$, dan mean untuk kedua variabel input yakni kurang dari 0,05 $(P<0,05)$. Hal ini mengindikasikan bahwa kedua variabel input memiliki pengaruh yang signifikan terhadap output (tenacity).

\section{Intersection Plot Parameters}

Intersection plot digunakan untuk melihat interaksi gabungan terhadap variabel respon, yaitu dengan melihat adanya perpotongan grafik dari masing-masing parameter yang diukur. Perpotongan grafik-grafik satu sama lain menandakan adanya interaksi di antara keduanya. ${ }^{26}$ Gambar 5 menunjukkan interaksi $S / N$ ratio kedua variabel terhadap respon untuk nilai $S / N$ ratio dan rata-rata tenacity. Dari kedua grafik yang diberikan, terlihat tidak ada perpotongan pada kedua variabel input. Hal ini dapat dipahami karena pengaruh draw ratio terhadap tenacity berbanding terbalik dengan pengaruh suhu terhadap tenacity.

\section{KESIMPULAN}

Nilai rata-rata respon tenacity dan tertinggi dicapai pada iterasi ke-13. Tenacity tertinggi dicapai ketika pengaturan (setting) draw ratio di level ke-4 dan suhu di level ke-1. Dari data ini, dapat disimpulkan bahwa besarnya nilai pengaturan (setting) draw ratio yang diberikan mempengaruhi respon secara positif (berbanding lurus) terhadap tenacity, sedangkan untuk pengaturan (setting) suhu yang diberikan mempengaruhi respon secara negatif (berbanding terbalik) terhadap tenacity. Dari analisis ANOVA, kedua parameter input memberikan pengaruh yang signifikan terhadap output. Penelitian ini telah memberikan solusi terhadap optimasi proses produksi benang DTY $150 \mathrm{D} / 96 \mathrm{~F}$ sehingga variabel tenacity bisa dikendalikan agar memenuhi spesifikasi yang ditetapkan. Penelitian lanjutan akan dilakukan untuk mengetahui pengaruh draw ratio dan suhu variabel respon gabungan antara tenacity, elongation, dan filament force.

\section{PUSTAKA}

1. N, G. A Review of Some Significant Research Trends in Yarn Texturising. Res. Dev. Mater. Sci. 4, 369-372 (2018).

2. Wellknown. Draw Textured Yarn. Wellknown.co.in https://www.wellknown.co.in/dty-new/.

3. Anthony, R. B. Handbook of Properties of Textile and Technical Fibres. Woodhead (2018).

4. Fashola, K. O. \& Onemano, G. O. Studies on the Properties of Some Selected Polyester Textured Yarns. Man-Made Text. India 40, 272-275 (2012).

5. Gupta, A., V. B. \& Kothari, V. K. Manufactured Fibre Technology. Manufactured Fibre Technology (1997). doi:10.1007/978-94-011-5854-1.

6. Yildirim, K., Altun, S. \& Ulcay, Y. Relationship between yarn properties and process parameters in false-twist textured yarn. J. Eng. Fiber. Fabr. 4, 26-32 (2009).

7. Elmogahzy, Y. \& Farag, R. Tensile properties of cotton fibers. Handbook of Properties of Textile and Technical Fibres (Elsevier Ltd, 2018). doi:10.1016/B978-0-08-1012727.00007-9.

8. Van Nostrand, R. C. Design of Experiments Using the Taguchi Approach: 16 Steps to Product and Process Improvement. Technometrics vol. 44 (2002).

9. Daniyan, I. A., Mpofu, K. \& Adeodu, A. O. 
Optimization of welding parameters using Taguchi and response surface methodology for rail car bracket assembly. (2018).

10. Pérez Pozo, L., Fernando Olivares, Z. \& Orlando Durán, A. Optimization of welding parameters using a genetic algorithm: A robotic arm-assisted implementation for recovery of Pelton turbine blades. Adv. Mech. Eng. 7, 1-17 (2015).

11. Gunawan, E., Sukarman, S., Shieddieque, A. D. \& Anwar, C. Optimasi Parameter Proses Resistance Spot Welding pada Pengabungan Material SECC-AF. (2019).

12. Sahithi, V. V.D., Malayadri, T. \& Srilatha, N. Optimization of turning parameters on surface roughness based on Taguchi technique. Mater. Today Proc. 18, 3657-3666 (2019).

13. Sukarman, S., Sitorus, I. R., Aribowo, B., Rajab, D. A. \& Heryadi, Y. Optimasi Parameter Proses Powder Coating pada Plat Electro Galvanized. in Prosiding SEMNASTERA (Seminar Nasional Teknologi dan Riset Terapan) 110-115 (2019).

14. Kaynak, H. K. \& Babaarslan, O. Breaking Strength and Elongation Properties of Polyester Woven Fabrics on the Basis of Filament Fineness. J. Eng. Fiber. Fabr. 10, 155892501501000 (2015).

15. Erbil, Y., Babaarslan, O. \& Ilhan, I. A comparative prediction for tensile properties of ternary blended open-end rotor yarns using regression and neural network models. J. Text. Inst. 109, 560-568 (2018).

16. Wickramasinghe, G. L. D. \& Foster, P. W. Investigation of the influence of effect-yarn draw and effect-yarn overfeed on texturing performance: comparison between air-jet and steam-jet textured yarn. Fash. Text. 1, 1-16 (2014).

17. Asghar, A., Ahmad, M. R. \& Yahya, M. F. Effects of metal filament's alignment on tensile and electrical properties of conductive hybrid cover yarns. Fash. Text. 3, (2016).

18. Semnani, D., Hassani, F., Hadjianfar, M. \& Rezazadeh Tehrani, P. Optimizing the impact resistance of high tenacity Nylon 66 weft knitted fabrics via genetic algorithm. Fash. Text. 3, (2016).

19. Amjad, A. I. \& Kumar, R. Effect of Fibre Fineness and Noil Extraction on the Different Shade Depths of Melange Yarns. J. Inst. Eng.
Ser. E 101, 33-43 (2020).

20. Malik, S. A., Farooq, A., Gereke, T. \& Cherif, C. Prediction of blended yarn evenness and tensile properties by using artificial neural network and multiple linear regression. Autex Res. J. 16, 43-50 (2016).

21. Sekerden, F. Investigation on the unevenness, tenacity and elongation properties of bamboo/cotton blended yarns. Fibres Text. East. Eur. 86, 26-29 (2011).

22. Bhatti, M. R. A., Tausif, M., Mir, M. A., Umar, M. \& Cassidy, T. Effect of key process variables on mechanical properties of blended vortex spun yarns. J. Text. Inst. 110, 932-940 (2019).

23. Nabi, K. A., Nafis, A. \& Ramij, H. Comparison of Several Cotton Yarn Properties before and after Conditioning. Int. J. Text. Sci. 6, 88-91 (2017).

24. ASTM D 2256. Standard Test Method for Tensile Properties of Yarns by the SingleStrand Method 1. vol. 07 1-15 (2002).

25. Mintab. Select the options for Analyze Taguchi Design (Static). https://support.minitab.com/enus/minitab/19/help-and-how-to/statisticalmodeling/doe/how-to/Taguchi /analyzeTaguchi -design/perform-the-analysis/selectthe-options-static-design/?SID=63406.

26. Arnold, S. F. Design of Experiments with MINITAB. The American Statistician vol. 60 (2006).

27. CASTILlO, E. DEL. Process Optimization A Statistical Approach. (Springer New York, 2007).

28. Fibre, D. Tenacity. Dominion Fibre https://dominionfiber.com/calculator-tool/ (2020).

29. R. Bunsell, A. Handbook of tensile properties of textile and technical fibres. (Woodhead Publishing Limited, 2009).

30. Atkinson, C. False Twist Textured Yarns: Principles, Process. and Appl. False Twist Textured Yarns: Principles, Processing and Applications (2012). doi:10.1533/9780857095596.

31. Ross, P. J. Taguchi Techniques for Quality Engineering. (Tata McGraw-Hill, 2005). 
Arena Tekstil Vol. 35 No. 2, 2020 : 77-86 